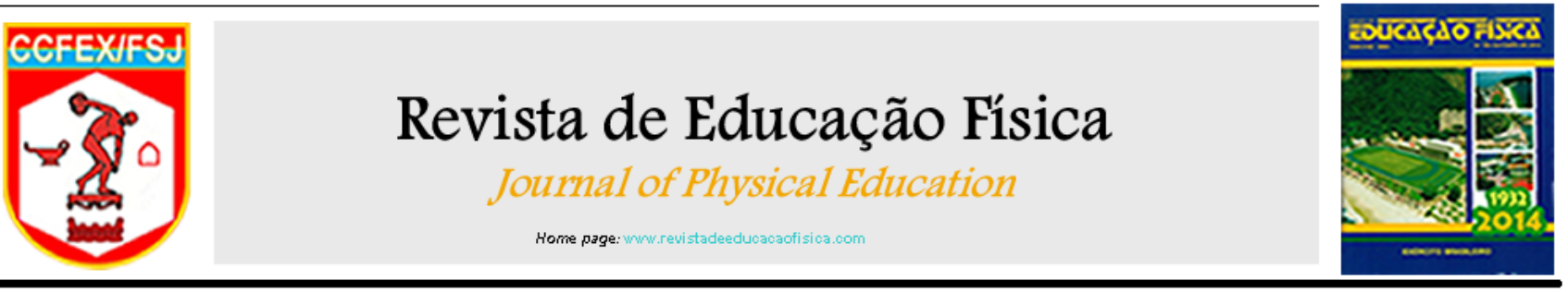

Resumo

\title{
Influência da modulação da frequência de passada sobre a frequência cardíaca e comprimento de passada durante uma corrida de $\mathbf{4 0 0}$ metros
}

Wesley Albano Ferreira Bsci, Rodrigo Rico Bini PhD

Introdução: A melhor relação entre comprimento e frequência de passada na corrida é objetivo de diversos estudos, porém a literatura não apresenta dados referentes à distância de 400 metros.

Objetivo: 0 presente estudo verificou a influência da modulação da frequência de passada no desempenho na corrida de 400 metros, analisando a frequência cardíaca e o comprimento da passada.

Métodos: Participaram do estudo 10 homens saudáveis $(25,9 \pm 3)$, corredores amadores com experiência na corrida de 400 metros. Foram realizadas três séries de 400 metros com intervalos de 5 minutos de repouso. Uma série foi realizada na frequência de passada preferida, outra com frequência $10 \%$ menor e outra com frequência $10 \%$ maior. Houve randomização da ordem das séries entre os participantes e a frequência cardíaca foi monitorada durante todos os testes e durante o repouso. Os dados de comprimento e frequência de passada, frequência cardíaca média durante a corrida, frequência cardíaca máxima e amplitude da frequência cardíaca na recuperação foram comparados utilizando testes $t$ de Student, associados à avaliação da magnitude das diferenças (effect sizes - ES). Efeitos substanciais foram considerados quando grandes magnitudes de diferença $(E S>0,8)$ e $\mathrm{p}<0,05$ foram observados.

Resultados: Houve diferença significativa entre os comprimentos de passada $(p<0,05$ e $E S>0,8)$ e entre as frequências de passada maior e menor $(p<0,01$ e $E S=1,51)$ e preferida e menor $(p=0,03$ e $E S=1,05)$. Contudo, entre a frequência de passada preferida e maior, frequência cardíaca média durante a corrida, frequência cardíaca máxima e amplitude desta no período de recuperação não se observou diferença significativa ( $p>0,05$ e $E S<0,8)$.

Conclusão: Independentemente da frequência de passada utilizada não houve diferença significativa na frequência cardíaca média durante a corrida, frequência cardíaca máxima e amplitude da frequência cardíaca durante a recuperação. 